\title{
Maternal smoking during pregnancy and early development of overweight and growth deficit in children: an analysis of survival
}

\author{
Poliana Cristina de Almeida Fonseca 1 \\ Carolina Abreu de Carvalho 2 \\ Vitória Abreu de Carvalho 3 \\ Andréia Queiroz Ribeiro 4 \\ Silvia Eloiza Priore 5 \\ Sylvia do Carmo Castro Franceschini 6 \\ Sarah Aparecida Vieira 7 \\ 1 Centro de Ciências Fisiológicas. Universidade Federal do Maranhão. São Luís, MA, Brasil. \\ 2 Departamento de Desenvolvimento Educacional. Instituto Federal do Maranhão. Rodovia MA-225, Km 04. Povoado Santa Cruz. Barreirinhas, MA \\ Brasil. CEP: 65590-000. Email: carolcarvalho91@gmail.com \\ 3 Universidade Federal do Maranhão. São Luís, MA, Brasil. \\ 4-6 Departamento de Nutrição e Saúde. Universidade Federal de Viçosa. Viçosa, MG, Brasil. \\ 7 Universidade Federal do Espírito Santo. Vitória, ES, Brasil.
}

\begin{abstract}
Objectives: to evaluate the association between smoking during pregnancy and nutritional status.

Methods: cohort study with a sample of 460 children in the baseline. The children were assessed four times, being measured for weight and length to be converted in indexes length forage (L/A) and body mass index forage (BMI/A) in Z-score. The time until occurrence of growth deficit and overweight was calculated in days and compared to maternal smoking during pregnancy. To assess the association between smoking during pregnancy and the outcomes, a Hazard Ratio by Cox regression was obtained, adjusting by confounding variables selected from Directed Acyclic Graphs (DAG)

Results: the time until occurrence of growth deficit and overweight was lower in children whose mothers smoked during pregnancy. Smoking during pregnancy was a risk factor for length deficit $(H R=2.84 ; C 195 \%=1.42$ to 5.70$)$ and for overweight $(H R=1.96 ; C 195 \%=$ 1, 09 to 3.53), even after the adjustment.

Conclusions: maternal smoking was a changeable factor associated with anthropometric outcomes, which demonstrates the need for actions to combat smoking during pregnancy in order to prevent early nutritional deviations.
\end{abstract}

Key words Smoking, Pregnancy, Child, Overweight, Growth 


\section{Introduction}

The deleterious effects of maternal smoking during pregnancy are well established on intrauterine growth, weight and length at birth. ${ }^{1-3}$ However, the causal effect of smoking during pregnancy on postnatal infant growth is still controversial, especially during the early postnatal period. The studies by Koshy et al. ${ }^{1}$ and Matijasevich et al. ${ }^{2}$ have shown an association between maternal smoking during pregnancy and development of growth deficit or overweight in childhood. In contrast, other authors did not find such association. ${ }^{3}$

It has been described a fetal programming mechanism by which maternal smoking during pregnancy interferes with postnatal growth. 4,5 Based on the theories of the developmental origins of health and disease (DOHaD), it is believed that smoking during pregnancy causes fetal hypoxia, compromising intrauterine growth. This intrauterine growth deficit would be decisive for the length/height deficit in childhood and in later life stages. However, in children who had IUGR, the occurrence of catch-up (accelerated postnatal growth) would provide greater weight gain, predisposing them to overweight. 6

The first year of life is a critical period of childhood since it is the phase with the highest growth rate, especially during the first six months. 7,8 Therefore, detailed analysis with repeated measures throughout this period allows a more accurate evaluation of when changes in nutritional status begin to occur during childhood. Few studies apply repeated measures in the first year of life.3,4

The study of causal significance of the association between maternal smoking during pregnancy and deleterious effects on postnatal infant growth is strongly influenced by socioeconomic confounding factors. ${ }^{2}$ Most studies that propose to analyze this effect have been conducted in high-income countries. $3,9,10$ However, it is important for this causal association to be explored further in low-and middleincome countries in order to verify whether the differences in socio-economic structure modify the findings.

In this context, our goal was to determine the effect of exposure to maternal smoking during pregnancy on the occurrence of length deficit and overweight from birth up to sixth month of life. As we have repeated weight and length measurements during this period, it is possible to analyze more precisely the time until these outcomes occur in children. Our hypothesis is that smoking during pregnancy is associated independently to the development of length deficit and overweight in children that were followed from up until they were six months old.

\section{Methods}

This is a prospective cohort study of children that were followed up from birth until the sixth month of life in the city of Viçosa, Minas Gerais (MG). It is located in Zona da Mata Mineira (Minas Gerais Wood Zone), with an area of $299,418 \mathrm{~km}^{2}$ and an estimated population in 2014 of 76,745 residents with an annual US\$ $3,274.30$ gross domestic product (GDP) per capita. Mothers of children born and living in the city were invited to participate in the survey from October 2011 to October 2012. The invitation was made in the only hospital that performed deliveries. After signing the Consent Terms, the children had their birth data recorded. One month later, the first evaluation was scheduled at the Viçosa's Town Polyclinic, reference location for immunization in the city, where it was also carried out evaluations on the second, fourth and sixth month of life of the children.

A pilot study was conducted at the same place where the data were collected, with children in the same age group and with the same characteristics of children belonging to the main study. Prior to the start of data collection, all team members were trained in the application of questionnaire and in anthropometric techniques for standardization of measures.

The exclusion criteria were: living in another city, presenting congenital disorders or syndromes, multiple pregnancies and being in the Neonatal Intensive Care Unit.

From October 2011 to October 2012, the maternity hospital in which the research was conducted reported that 806 children had been born. Congenital disorders or syndromes (15), multiple pregnancies (52) and being in the Neonatal Intensive Care Unit (72) were non-inclusion criteria. There were losses due to hospital discharge or refusal (117) and children who did not attend the first evaluation were excluded (90). After exclusions and losses, 460 children showed up for evaluation in the first month of life. There were losses in the following months due to mothers who did not attend to the collection site. In the second month 390 children were evaluated, in the fourth month 335 and in the sixth month 284 .

The selection of variables included in the adjustment was carried out through the use of directed acyclic graphs (DAG). This strategy is used to view confounding bias through the construction of a theoretical model and application of heuristic rules, by 
which it is possible to identify the explanatory variables that need to be included in the statistical adjustment. Thus, it avoids unnecessary adjustments and reduces the occurrence of confounding and selection bias on estimates generated. ${ }^{11,13}$

Dagitty ${ }^{\circledR}$ browser was used for the construction of the DAG. A theoretical model was built describing the relationship between smoking during pregnancy and overweight/obesity, as well as another model considering length deficit as the outcome. We assumed the hypothesis that exposure to smoking during pregnancy can cause length deficit (Figure 1a) and overweight (Figure 1b) during the first semester of life. Based on literature, for both theoretical models, the variables family income, maternal education and number of prenatal visits were considered to be associated with both exposure and outcome. Several other socioeconomic, behavioral, maternal, perinatal and dietary variables were taken into account during the construction of DAG and their relationships are explained in theoretical models.

Figure 1

Directed acyclic graphs of the association between smoking during pregnancy and length deficit (a) or overweight (b) in children.

\section{Figure 1A}

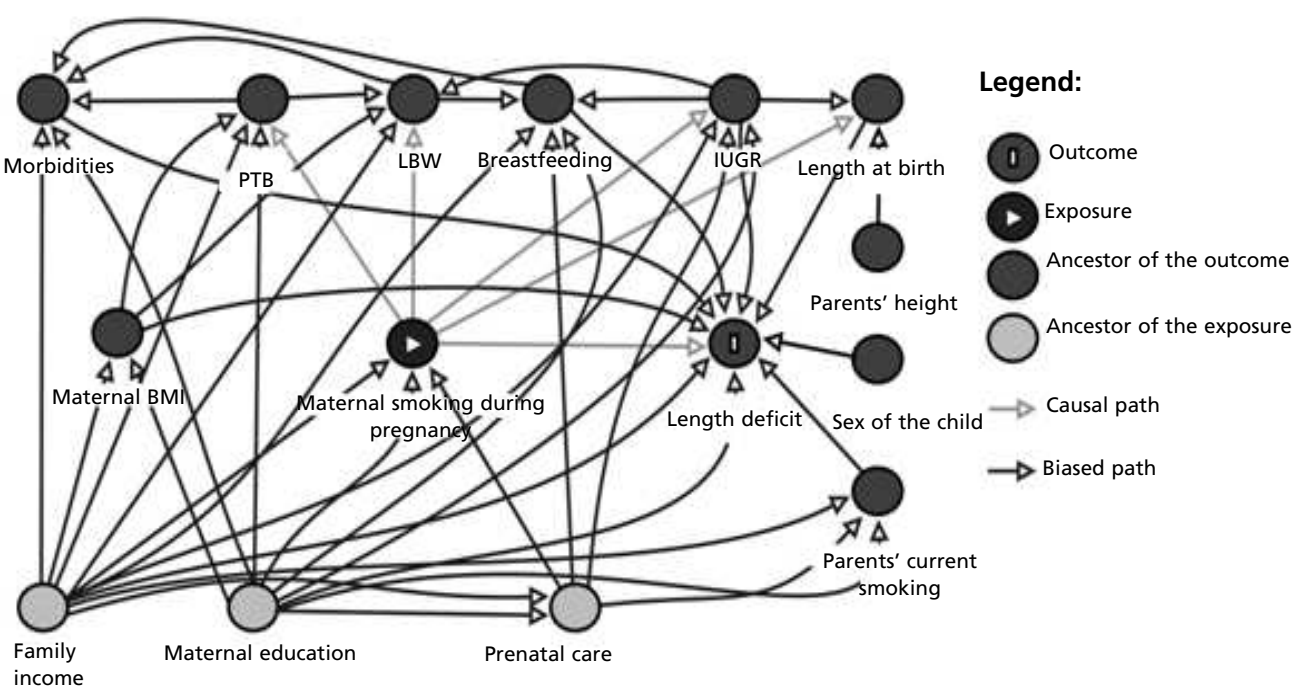

Figure 1B

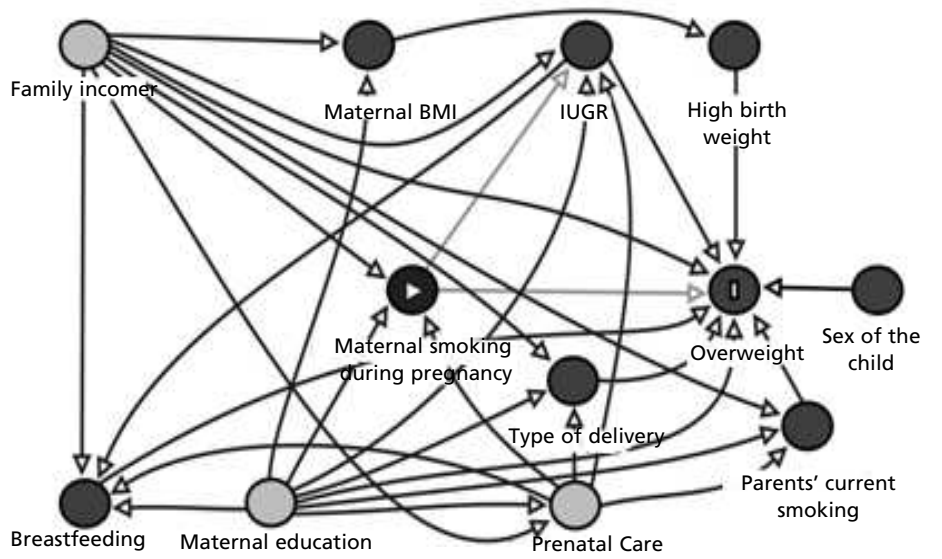

Legend:

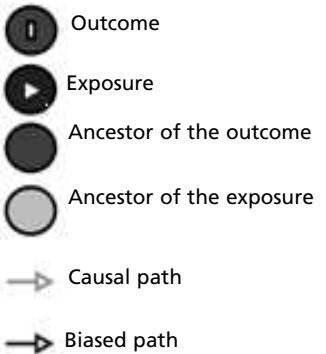

PTB = preterm birth; IUGR= Intrauterine Growth Restriction; LBW= Low Birth Weight; $B M I=$ Body Mass Index. 
In each evaluation, a semi-structured questionnaire was applied to access sociodemographic and mother's lifestyle data and dietary and perinatal information of the children. The mother was asked if she smoked during pregnancy and her response was classified as yes or no. Passive smoking and the intensity of smoking were not evaluated. Mother's education information was collected in years of study and categorized into 0 to $8 ; 9$ to 11 ; and greater than or equal to 12 years. The family's income was distributed into tertiles. The number of prenatal visits was categorized as adequate ( $\geq 6$ visits) and inappropriate ( $<6$ visits).

The weight and length were evaluated during every month of follow-up, with the weight being measured by the team using a digital, pediatric scale, always without clothes or diaper. The length was measured with the child naked, using a wooden infantometer. For admeasurement of both measures, techniques standardized by the $\mathrm{WHO}^{12}$ were adopted.

Weight and length data were converted into the indexes: body mass index for age (BMI/A) and length for age (L/A) in Z-score. For the Z-score calculations we used the Who-Antro software version 2.0.1.13 For classification of these indexes, cutoffs recommended by $\mathrm{WHO}^{14}$ were used. Overweight (risk of overweight + overweight) was considered for values greater than one standard deviation according to the $\mathrm{BMI} / \mathrm{A}$ indicator. Deficit in length was diagnosed through the L/A indicator when the values obtained were lower than - 2 standard deviations.
Statistical analyzes were performed on Stata ${ }^{\circledR}$ software, version 14.0.

The time until the occurrence of overweight (failure) and deficit in length (failure) was calculated in days. The curves of time until the occurrence of overweight and length deficit in relation to smoking during pregnancy were described using the KaplanMeier method. The log rank test was performed to compare these curves.

The minimum set of variables necessary for confounding control in the adjusted analysis was: family income, maternal education and number of prenatal visits. The effect of explanatory variables over time until the occurrence of overweight and length deficit was assessed by Cox regression, calculating the Hazard Ratio as association measure. The level of significance was set at $5 \%$.

This study was approved by the Ethics Committee on Human Research of the Federal University of Viçosa and funded by Minas Gerais State's Foundation for Research.

\section{Results}

The prevalence of maternal smoking during pregnancy was $7.6 \%$. At six months, $5.4 \%$ of the children presented low length for age and $25.4 \%$ presented overweight. The prevalence of children with prematurity and low birth weight was $6.5 \%$ and $5.5 \%$, respectively. The majority of the mothers presented education between 9 and 11 years and the average income was 368.75 USD. Adolescent mothers accounted for $17.4 \%$ of the sample.

Figure 2

Overweight survival curve according to exposure to smoking during pregnancy in children through the first six months of life, Viçosa - MG, 2011-2013.

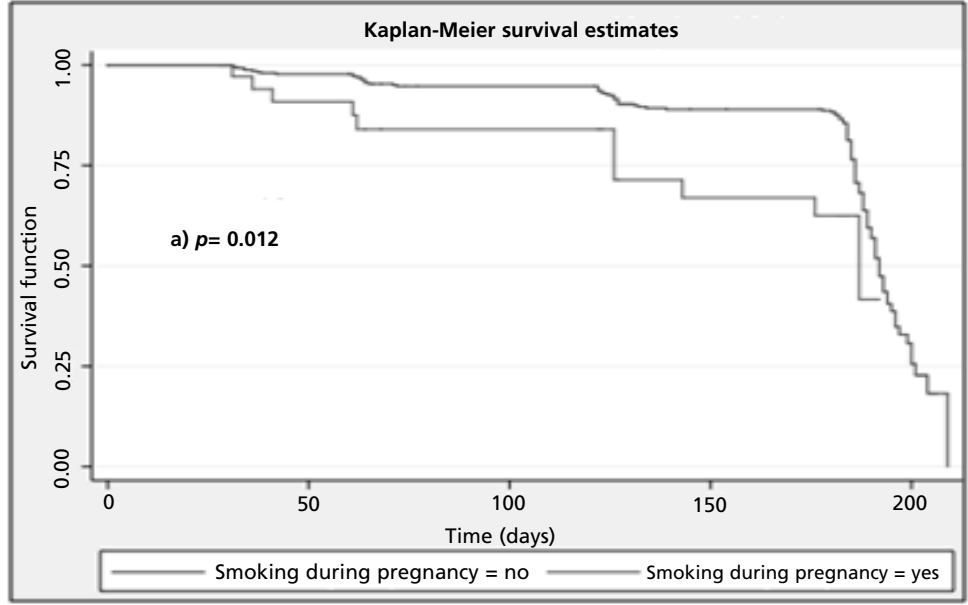


We observed that the survival time until the occurrence of overweight was lower in children whose mothers smoked during pregnancy (Figure 2). The average survival time until the overweight development was 158.5 days in children whose mothers did not smoke during pregnancy, compared to 114.5 days in those whose mothers smoked. The $p$ value of the log rank test was $<0.012$, thus indicating a significant difference between the curves.

The survival curve analysis for the occurrence of length deficit indicates that children of mothers who smoked during pregnancy developed length deficit earlier $(p<0.004)$. The average survival time until the occurrence of length deficit was 117.4 days in children whose mothers smoked, compared to 156.5 days in those whose mothers did not smoke (Figure $3)$.
Table 1 presents the results of the final model adjusted to the variables listed by the DAG for the relationship between smoking during pregnancy and overweight using Cox regression. Smoking during pregnancy was associated with the occurrence of overweight in children regardless of maternal education, family income and adequacy of the number of prenatal visits $(p=0.025)$. The Hazard Ratio (HR) of smoking during pregnancy variable showed that there was a $1.96(\mathrm{CI} 95 \%=1.09$ to 3.53$)$ times higher likelihood for children to develop overweight if the mother was a smoker at the time of gestation.

Smoking during pregnancy was also an independent risk factor for length deficit among children $(\mathrm{HR}=2.84, \mathrm{CI} 95 \%=1.42$ to 5.70$)$, as shown in Table 2.

Figure 3

Length deficit survival curve according to exposure to smoking during pregnancy in children through the first six months of life, Viçosa - MG, 2011-2013.

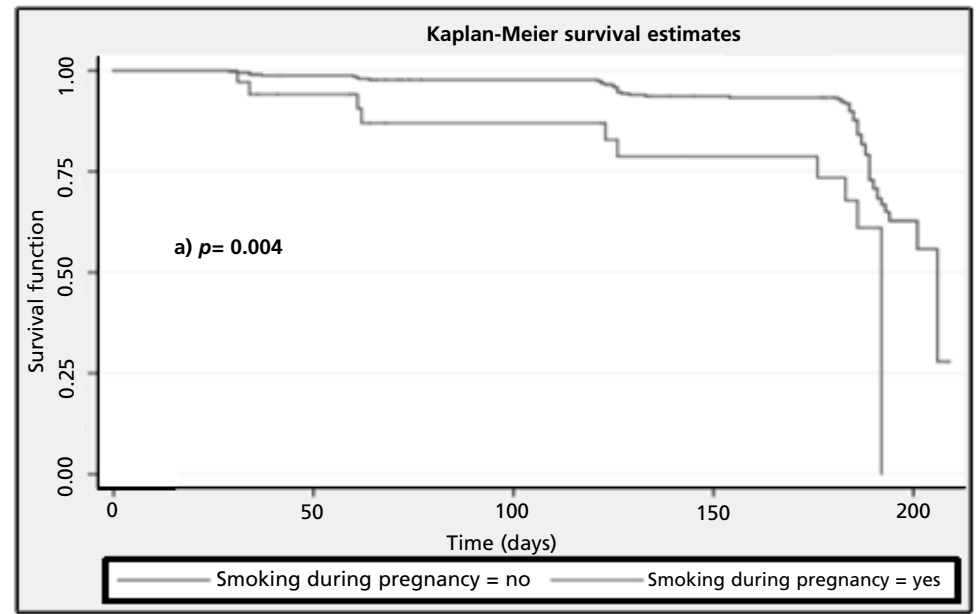




\section{Table 1}

Multiple analysis of smoke during pregnancy and other factors associated with overweight in children through the first six months of life, Viçosa, 2011-2013.

\begin{tabular}{|c|c|c|c|}
\hline Variables & Hazard Ratio & $\mathrm{Cl} 95 \%$ & $p^{*}$ \\
\hline \multicolumn{4}{|c|}{ Maternal smoking during pregnacy } \\
\hline No & 1.00 & & \\
\hline Yes & 1.96 & $1.09-3.53$ & 0.025 \\
\hline \multicolumn{4}{|l|}{ Family income } \\
\hline $3^{\text {rd }}$ tertile & 1.00 & & \\
\hline $2^{\text {nd }}$ tertile & 0.78 & $0.50-1.22$ & 0.269 \\
\hline 1st tertile & 0.71 & $0.44-1.14$ & 0.152 \\
\hline \multicolumn{4}{|c|}{ Maternal education (years of study) } \\
\hline$\geq 12$ & 1.00 & & \\
\hline $9-11$ & 1.08 & $0.62-1.89$ & 0.787 \\
\hline $0-8$ & 1.79 & $0.99-3.26$ & 0.055 \\
\hline \multicolumn{4}{|c|}{ Number of prenatal visits } \\
\hline Adequate & 1.00 & & \\
\hline Inadequate & 1.05 & $0.65-1.70$ & 0.846 \\
\hline
\end{tabular}

*Cox Regression.

Table 2

Multiple analysis of smoke during pregnancy and other factors associated with the occurrence of length deficit in children through the first six months of life, Viçosa, 2011-2013.

\begin{tabular}{|c|c|c|c|}
\hline Variables & Hazard Ratio & $\mathrm{Cl} 95 \%$ & $p^{*}$ \\
\hline \multicolumn{4}{|c|}{ Maternal smoking during pregnacy } \\
\hline No & 1.00 & & \\
\hline Yes & 2.84 & $1.42-5.70$ & 0.003 \\
\hline \multicolumn{4}{|c|}{ Maternal education (years of study) } \\
\hline$\geq 12$ & 1.00 & & \\
\hline $9-11$ & 0.82 & $0.37-1.80$ & 0.619 \\
\hline $0-8$ & 1.30 & $0.56-3.01$ & 0.536 \\
\hline \multicolumn{4}{|l|}{ Family income } \\
\hline 3rd tertile & 1.00 & & \\
\hline 2nd tertile & 1.17 & $0.61-2.26$ & 0.639 \\
\hline 1st tertile & 1.03 & $0.51-2.08$ & 0.938 \\
\hline \multicolumn{4}{|c|}{ Number of prenatal visits } \\
\hline Adequate & 1.00 & & \\
\hline Inadequate & 1.62 & $0.90-2.92$ & 0.109 \\
\hline
\end{tabular}

*Regressão de Cox. 


\section{Discussion}

This study showed a significant independent effect of maternal smoking during pregnancy on growth deviations (overweight and length deficit) in children followed up until they were six months old These findings contribute to a better understanding of the influence of maternal smoking and its effects on the child's nutritional status and growth during the early postnatal period.

Survival time until the occurrence of overweight among children whose mothers smoked during pregnancy was significantly lower when compared to children of non-smoking mothers. That is, children exposed to smoking during pregnancy developed overweight first in comparison to their counterparts. After adjusting for family income, mother's education and number of prenatal visits, this association remained significant, indicating the independent effect of maternal smoking.

The association between maternal smoking during pregnancy with overweight in children has been reported in some studies, but only at the end of the first year of life and during later periods of childhood.2,5,10,15,16 Matijasevich et al. 2 observed the lack of association between maternal smoking and overweight in children with 3 months of age, but at 12 months they found a higher z-score of BMI for age in those children exposed to smoking during pregnancy. It has been shown that, although infants of smoking mothers present lower birth weight, as the child gets older higher BMI values are observed.2,4,5,10 However, we detected the early occurrence of overweight, caused independently by the effect of maternal smoking during pregnancy. This indicates that the deleterious effects of smoking on children's growth can manifest even earlier than what had been shown in the literature. 17

It is well known that smoking during pregnancy has a negative effect on the placenta, impairing blood flow and, thus, the supply of oxygen and micronutrients for the fetus. ${ }^{18}$ Due to the vasoconstrictor action of nicotine and fetal hypoxia, the child may have low birth weight and length. ${ }^{3}$ These children tend to have more "growth catch-up" and become more prone to being overweight during childhood. ${ }^{6}$ Consistent with this hypothesis and with the results of our study, Timmermans et al., 10 while studying children of the KOALA Birth Cohort Study in the Netherlands, showed that children of smoking mothers had greater weight gain during the first year of life despite being born with low birth weight. In our study, birth weight was considered in the DAG preparation, however, after the application of the back door criterion, the adjustment for this variable was not necessary.

In our study, maternal smoking during pregnancy was also an independent cause for the development of length deficit in children up to the sixth month of life. The survival rate was lower for children exposed to maternal smoking during pregnancy, with an average of 117.5 days until the occurrence of length deficit in children. This finding suggests the short time required for maternal smoking during pregnancy to cause impaired linear growth.

We have obtained a high magnitude of association between maternal smoking during pregnancy and growth deficit. The risk for the occurrence of this outcome in children exposed to maternal smoking during pregnancy was 2.84 times, after the adjustment of the confounding variables suggested by DAG. Other studies show the negative effect of maternal smoking on children at different ages during short and long term growth.1,2,19 Howe et $a l ., 3$ in a study that followed British children from birth to 10 years, showed that although the children of smoking mothers have presented greater linear growth from birth to 10 months of life, after such period these children remained with a shorter height when compared to the children of mothers who did not smoke.

Researches with Brazilian children also demonstrated the negative effect of maternal smoking during pregnancy on the child's growth.2,18,20 Similar to our findings, the study done by Gonçalves et al.20 showed that smoking during pregnancy was associated independently to the length/age index in children with less than two years. According to Matijasevich et al.,2 there was an association between smoking during pregnancy and the reduction of the length/age z-score in children with 3, 12, 24 and 48 months old. The cohort study done by Muraro et al. ${ }^{18}$ suggested the deleterious effects of smoking during pregnancy in small stature from birth to adolescence.

The scientific literature highlights the great importance of breastfeeding on infant growth and it is considered a protective factor for the development of nutritional disorders. 21,22 The two DAGs built in the present study point to the role of breastfeeding in the analyzed outcomes. However, after applying the heuristic rules of directional separation, the variable breastfeeding does not compose the minimum set of variables for adjustment. Therefore, according to the DAG theory, the variables included in the adjustment in this study are able to control the confounding without the need to include breastfeeding. The concept of confounding defines that a 
variable to be confounding must simultaneously cause the exposure and outcome under study. ${ }^{23}$ Thus, it is understood that the child's diet cannot be considered a confounding variable, since it is related only to the nutritional status (outcome) and not to the occurrence of maternal smoking during pregnancy (exposure).

This study has limitations, such as the occurrence of tracking losses common in cohort studies. However, we emphasize that during the survival analysis the tracking losses are considered as censures and, subsequently, are used to calculate the cumulative survival probability function before being considered as losses. This allows the best use of available data, mitigating the effects of follow-up losses. Besides, in a former study 24 that used the same sample as the one used in this study, when comparing the characteristics of assessed individuals with unaccompanied ones, there were no statistically significant differences for the variables: maternal smoking, family income, maternal education and adequate number of prenatal visits.

We emphasize that it was not the objective of the present study to study the effect of smoking duration or intensity on infant nutritional status. We investigate only the presence or absence of this exposure and we observe the influence of this variable on nutritional deviations. Other studies may be carried out to evaluate the effect of smoking duration or intensity on infant nutritional status.

Moreover, this study also shows strong points. The longitudinal design made it possible to monitor the children's growth during the first six months of their life. The design of this study makes it possible to analyze the causal effect of smoking during pregnancy on growth in the critical period which is the first year of life. The survival analysis also strengthens the present study, allowing to check the time until the occurrence of the outcomes that were analyzed, showing the effect of maternal smoking during pregnancy on the development of both outcomes, even in the early postnatal period. We emphasize that this type of analysis has been little explored in causality studies between smoking during pregnancy and growth deviations in childhood, probably because most of the studies did not have many repeated measurements during the periods analyzed.

The use of four repeated measurements during the first semester of life is another strong point of this study, as it enables to conduct a thorough and accurate analysis of the time until occurrence of outcomes in children. Finally, we point out that the use of DAG has largely contributed to the study of causality in epidemiology, since it allows to identify, based on a theoretical model and application of heuristic rules, which variables need to be included during the adjusted analysis. The selection of a minimum set of variables required to control confounding and selection bias avoids unnecessary adjustments when obtaining estimates.12,13 Therefore, we believe that this tool contributed to the identification of a more accurate estimate of the causal effect of maternal smoking during pregnancy on the growth deviations analyzed. Nevertheless, it is not possible to rule out the possibility of residual confounding.

We found a significant association between maternal smoking during pregnancy and overweight and length deficit in the first six months of life. This finding points to the negative effects of exposure to smoking during pregnancy at an early stage of growth during the postnatal period. Furthermore, it suggests that this exposure causes, independently, both growth deficit (chronic malnutrition indicator), and the development of childhood overweight. We suggest the discouragement of smoking among pregnant women, since this is a changeable risk factor for early onset of nutritional disorders among children. For mothers who smoked during pregnancy, more attention is recommended during pediatric follow-up in order to minimize other environmental risk factors for nutritional deviations.

\section{References}

1. Koshy G, Delpisheh A, Brabin BJ. Dose response association of pregnancy cigarette smoke exposure, childhood stature, overweight and obesity. Eur J Public Health. 2011; 21: 286-91.

2. Matijasevich A, Brion MJ, Menezes AM, Barros AJ, Santos IS, Barros FC. Maternal smoking during pregnancy and offspring growth in childhood: 1993 and 2004 Pelotas cohort studies. Arch Dis Child. 2011; 96: 519-25.

3. Howe LD, Matijasevich A, Tilling K, Brion MJ, Leary SD,

Smith GD, Lawlor DA. Maternal smoking during pregnancy and offspring trajectories of height and adiposity: comparing maternal and paternal associations. Int $\mathrm{J}$ Epidemiol. 2012; 41: 722-32.

4. Suzuki K, Kondo N, Sato M, Tanaka T, Ando D, Yamagata $Z$. Gender differences in the association between maternal smoking during pregnancy and childhood growth trajectories: multilevel analysis. Int J Obes (Lond). 2011; 35: 53-9. 
5. Suzuki K, Kondo N, Sato M, Tanaka T, Ando D, Yamagata Z. Maternal smoking during pregnancy and childhood growth trajectory: a random effects regression analysis. J Epidemiol. 2012; 22: 175-8.

6. Ino T. Maternal smoking during pregnancy and offspring obesity: meta-analysis. Pediatr Int. 2010; 52: 94-9.

7. Jaldin MdGM, Pinheiro FS, Santos AMd, Muniz NC. Crescimento infantil comparado com as referências NCHS e o padrão WHO/2006. Rev Nutr. 2013; 26: 17-26.

8. SBP. Avaliação nutricional da criança e do adolescente Manual de orientação. São Paulo: Sociedade Brasileira de Pediatria. Departamento de Nutrologia; 2009: 112.

9. Suzuki K, Sato M, Zheng W, Shinohara R, Yokomichi H, Yamagata Z. Childhood growth trajectories according to combinations of pregestational weight status and maternal smoking during pregnancy: a multilevel analysis. PLoS One 2015; 10: e0118538.

10. Timmermans SH, Mommers M, Gubbels JS, Kremers SP, Stafleu A, Stehouwer CD, Prins MH, Penders J, Thijs C. Maternal smoking during pregnancy and childhood overweight and fat distribution: the KOALA Birth Cohort Study. Pediatr Obes. 2014; 9: e14-25.

11. Textor J, Hardt J, Knuppel S. DAGitty: a graphical tool for analyzing causal diagrams. Epidemiol. 2011; 22: 745.

12. de Onis M, Onyango AW, Van den Broeck J, Chumlea WC, Martorell R. Measurement and standardization protocols for anthropometry used in the construction of a new international growth reference. Food Nutr Bull. 2004; 25: S2736

13. WHO. WHO Anthro for personal computers Manual: Software for assessing growth of the world's children. 2005 Geneva: WHO; 2005. Disponível em: http:/http://www.who.int/growthref/tools/en. Acesso em: abril de 2014; 2005 .

14. Brasil. Ministério da Saúde. Orientações para coleta e análise de dados antropométricos em serviços de saúde: norma técnica do sistema de Vigilância Alimentar e Nutricional - SISVAN. 2011. Disponível em: http://189.28.128.100/dab/docs/portaldab/publicacoes/orien tacoes_coleta_analise dados_antropometricos.pdf. Acesso em: 19 nov de 2014.

Received on November 01, 2017

Final version presented on March 13, 2018

Approved on April 03, 2018
15. Suzuki K, Sato M, Ando D, Kondo N, Yamagata Z. Differences in the effect of maternal smoking during pregnancy for childhood overweight before and after 5 years of age. J Obstet Gynaecol Res. 2013; 39: 914-21.

16. Suzuki K, Sato M, Zheng W, Shinohara R, Yokomichi H, Yamagata Z. Effect of maternal smoking cessation before and during early pregnancy on fetal and childhood growth J Epidemiol. 2014; 24: 60-6.

17. Suzuki K. Longitudinal analyses of childhood growth: evidence from Project Koshu. J Epidemiol. 2015; 25: 2-7.

18. Muraro AP, Goncalves-Silva RM, Moreira NF, Ferreira MG, Nunes-Freitas AL, Abreu-Villaca Y, Sichieri R. Effect of tobacco smoke exposure during pregnancy and preschool age on growth from birth to adolescence: a cohort study. BMC Pediatr. 2014; 14: 99

19. Martinez-Mesa J, Menezes AM, Gonzalez DA, Horta BL, Matijasevich A, Gigante DP, Hallal PC. Life course association of maternal smoking during pregnancy and offspring's height: data from the 1993 Pelotas (Brazil) birth cohort. J Adolesc Health. 2012; 51: S53-7.

20. Gonçalves-Silva RMV, Valente JG, Ferreira MG, Sichieri R. Tabagismo no domicílio e desnutrição em lactentes. Rev Nutr. 2009; 22: 19-27.

21. Longo GZ, Souza JMPd, Souza SBd, Szarfarc SC. Crescimento de crianças até seis meses de idade, segundo categorias de aleitamento. Rev Bras Saúde Mater Infant. 2005; 5 : 109 -

22. Gonçalves SC, Louzada MLC, Campagnolo PDB, Vitolo MR. Velocidade de ganho de peso e práticas alimentares no primeiro ano de vida em lactentes de baixo nível socioeconômico. Rev Nutr. 2012; 25: 555-63.

23. Greenland S, Pearl J, Robins JM. Causal diagrams for epidemiologic research. Epidemiol. 1999; 10: 37-48.

24. Fonseca PCA, Carvalho CA, Ribeiro SAV, Nobre LN, Pessoa MC, Ribeiro AQ, Priore SE, Franceschini S. Determinants of the mean growth rate of children under the age of six months: a cohort study. Ciên Saúde Coletiva. 2017; 22: 2713-26. 